Año XLIX. urtea

$124-2017$

Uztaila - abendua Julio - diciembre

Sor $20 x$

6

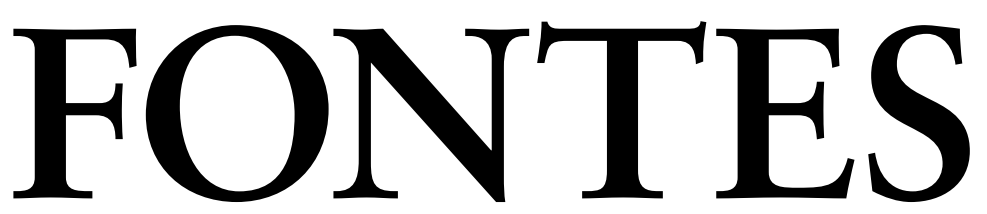

LINGVÆ

VASCONVM

STVDIA ET DOCVMENTA

SEPARATA

XVIII. mende erdialdeko

Etxalarko dotrina

Urtzi Reguero-UGarTe

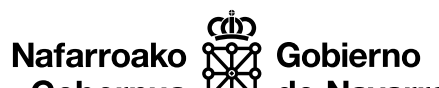

Gobernua 48 de Navarra 


\title{
XVIII. mende erdialdeko Etxalarko dotrina
}

\author{
Dotrina de Etxalar de mediados del siglo XVIII
}

\section{Doctrine of Etxalar of mid-eighteenth century}

\author{
Urtzi REGUERO-UGARTE \\ Euskal Herriko Unibertsitatea, UPV/EHU \\ urtzi.reguero@ehu.eus
}

\begin{abstract}
Lan hau ondoko ikerketa talde eta proiektuen baitan egina da: «Monumenta Linguae Vasconum (V): periodización y cronología» (FFI: 2016-76032-P), "Hizkuntzalaritza Teoriko eta Diakronikoa: Gramatika Unibertsala, Hizkuntza Indoeuroparrak eta Euskara» (UFI11-14) eta «Historia de la lengua vasca y lingüística histórico-comparada» (IT 698-13). Bestalde, Pello Apezetxea Zubiri Etxalarko apaizaren adeitasunari eta laguntzari esker eskutan izan dut dotrina jasotzen duen bataio-liburua eta, beraz, eskuizkribua ikusteko aukera; bihoazkio eskerrak hemendik. Orobat, Ekaitz Santazilia eta ohargile anonimoak eskertu behar ditut artikuluaren aurreko bertsio bati egindako iruzkin baliagarriengatik. Zalantzarik gabe, hobekuntza nabarmena izan du artikuluak beren oharrei esker. Halere, dauden huts guztiak nire-nireak dira.
\end{abstract}




\section{LABURPENA}

Artikulu honek XVIII. mendearen erdialdean Joan Bautista Sanzberro etxalartarrak idatzitako euskarazko dotrinaren edizio filologikoa dakar. Testuaren edizioarekin batera, hizkuntza-azterketa eta garai bertsuko beste testu batzuetako euskararekin egindako konparazioa ere badaude.

Gako hitzak: dotrinak; testu zaharrak; dialektologia; Sanzberro.

\section{RESUMEN}

Este articulo contiene la edición filológica de una breve doctrina cristiana escrita por Juan Bautista Sanzberro, de Etxalar, a mediados del siglo XVIII. Junto con la edición, también presentamos un análisis del euskera del texto y una comparación con el euskera de otros textos contemporáneos de la doctrina.

Palabras clave: doctrinas; textos antiguos; dialectología; Sanzberro.

\section{ABSTRACT}

In this work, we present a philological edition of a doctrine written in mid-eighteenth century by Joan Bautista Sanzberro from Etxalar (Navarre). In addition, we have done a language analysis of the Basque language employed in the text. To end with, we compare the variant used in the text with that employed in other contemporary texts.

Keywords: doctrines; old texts; dialectology; Sanzberro. 
1. Sarrera. 2. Egilea eta data. 3. Edizio irizpideak. 4. Testua. 5. Hizkuntza AZTERKETA. 6. FAKSIMILEA. 7. ERREFERENTZIAK.

\section{SARRERA}

Saiotxo honetan XVIII. mendearen erdialdean idatzitako euskarazko testu bat dakart. Hain zuzen ere, Bortzirietako Etxalar herriko elizan agertu zen aipatu lekukotasuna, eta bertan dago, oraindik, XVIII. mendearen lehen erdiko bataio-liburuan. Testua euskaraz idatzitako dotrina labur bat da, eta 1702-1749 bitarteko bataioak jasotzen dituen bigarren liburuaren lehen orrialdeetan dago eskuizkribua. Orotara, hiru orrialde ditu.

Lehenengoz, ustez behinik behin, Satrustegik (1978-79) eman zituen ezagutzera dotrinaren testu zati batzuk. Ondotik, osorik jaso zuen Euskal testu zaharrak I (78-80) bilduman.

Hona ekarritako edizioa berria da, Etxalarren dagoen jatorrizko eskuizkribuan oinarrituta. Edizioaz gain, egileari eta dotrinaren datari buruzko informazioa badakar saio honek. Akabuan, dotrinako euskararen azterketa bat dago, eta geografikoki hurbilekoak edo garaikideak diren beste testu batzuekin erkatu dut, zenbait kasutan: Miguel Elizalderen gutunak, Irungo testuak (Reguero, 2017), Baztango sermoiak (Lekaroz, 2006), Le Dauphin itsasontziko lapurterazko gutunak (Lamikiz, Padilla \& Videgain, 2015), Mikelestorena lesakarrak idatzitako Cerura nai duenac ar dezaquen vide erraza (1751). Eranskin moduan jatorrizkoaren irudiak eman ditut.

\section{EGILEA ETA DATA}

Dotrinak ez dakar urterik, ezta egilerik ere, baina liburuko gainerako testuen idazkera berbera denez, ziur egon gaitezke dotrinaren idazlea Joan Bautista Sanzberro dela. 
Duela gutxira arte, gutxi zen dotrina laburtto honen egileaz genekiena; orain, ordea, Lekarozek (2014) datu gehiago eman dizkigu.

Dirudienez, Sanzberro 1701eko irailaren 10ean jaio zen Etxalarko Iriartea etxean. Izandako ikasketen berri gutxi lortu duen arren, Lekarozek baieztatzen du berandu hasi zuela eliza-ibilbidea: 25 urte beteta zituenean. 1727ko ekainean hartu zuen Oiartzungo San Esteban elizan lehen ordena txikia; urte bereko abenduan Graduak hartu zituen Uharteko San Joan parrokian. 1728an Etxalarko Francisco Sanzberro apaizak kapilautza sortu zuen Etxalarren eta Joan Bautista Sanzberro aukeratu zuten kapilau. 1730ean bihurtu zen apaiz. 1730-1744 bitarteko bataio-liburuetako sinadurek erakusten dutenez, orduko Etxalarren zenbait apaiz zeuden, eta 1744ko azaroaren 18an agertzen da lehen aldiz Joan Bautista Sanzberroren sinadura. Hortik aurrera, tarteka agertzen da 1745eko azarora arte. Geroztik ez da haren sinadurarik ageri 1749ra arte. Hori horrela izanda, Lekarozek garbi ikusten du 1740. urtetik aurrera Etxalarko apaizetako bat izan zela, eta hainbatetan erretore-zereginak bete zituela.

Hain zuzen ere, Lekarozek hamarkada hartakotzat hartzen du dotrinatxoa: arestian aipatu denez, 1702-1749 bitarteko bataioak jasotzen dituen eliza-liburuan idatzi zuen; gainera, heriotza agirietan agertzen denez, 1751n hil zen Sanzberro. Beraz, hori jakinda eta liburuan 1749 bitarteko bataioak agertzen direla kontuan izanda, ante quem data 1749-1751n jar dezakegu, eta post quem data, beharbada, 1740an.

\section{EDIZIO IRIZPIDEAK}

Hemen aurkezten den honek edizio filologikoa izan nahi du. Horretarako, testuak duen jatorrizko grafia mantendu dut, baina hitzen banaketa eguneratu. Halaber, testuan aurkitutako hutsak oro zuzendu eta oharretan eman dut horren berri. Halere, eskuizkribuan falta den letraren bat gehitu dudanean, [ ] artean eman dut. Esan gabe doa, edizio hau paratzeko, Etxalarko elizan dagoen jatorrizko bertsioa erabili dudala. Horretaz gain, Satrustegiren (1987) edizioa ere eskura izan dut eta desberdintasunak oharretan jarri.

\section{TESTUA}

$<1>\mathrm{Ch}[\mathrm{r}]$ istau fidel gucia dago osoqui obligatua devociua yduquicera viocetic gurucera. Christo il cen gurucean, il biar dugu aren fedean. Il cen gure salbaceco, culpatic gu ateraceco. Artu biar ${ }^{1}$ dugu costumbrea eguiteco gurucea. Biar dugu ere ciñatu, alaber ere santiguatu. Cer da, bada, ciñacia? Iru guruce eguitea: copetan lenbicicoa, auban

1 biar] $<$ r $>$ lerro artean. 
gero bigarrena, yrugarrena bularretan. Beti iduquiceco etan ${ }^{2}$. Copetan libraceco eta gu apartaceco pensamentu gastuetaric, auban libraceco itz gastuetatic, bularretan libraceco eta gaisqui es eguiteco. Cer da, bada, oray, santiguacea ${ }^{3}$ ? Guruce bat eguitea copetatic bularretaraño ${ }^{4}$, soin batetic berceraño. Eguizu, bada, bereala, ni nacusazun besala ${ }^{5}$.

Siñestacen dut Jaungoyco ayta podore gucia duena baitan, ceruaren eta lurraren criazallia eta aren seme bacar Jesuchristo gure jauna baitan, cein concebitu baicen Espiritu Santuaren obraz eta graciaz. Yayo cen virgina Mariaganic, padecitu zuben Poncio Pilatosen podoriaren azpian. Cruxceficatu zuten, hil eta orci zuten. Iauci cen infernuetara eta irurgarren egunean viztu cen hiletaric. Ygan $^{6}$ cen ceruetara eta dago iarriric Jaungoico aita podore gucia duenaren ${ }^{7}$ escuñeco aldean. Andic etorrico da vicien eta ilen iuscacera. Siñestacen dut Espiritu Santua baitan. Eliza Santa Chatolicua ${ }^{8}$, santuen comunionia, vecatuen barcacioa, araguiaren biztea eta biciza seculacua. Amen.

$<2>$ Fedesco articuluac dire amalau. Zazpiac ${ }^{9}$ dagozca Jaungo[y]cotasunari ${ }^{10}$ eta verce zazpiac Jesuchristo gure Jaungoyco jaun eta gizon eguiazcoari ${ }^{11}$. Jangoicotasunari dagosquionac ${ }^{12}$ dire hoc. Lentabicicoa siñestea J[a]ungoyco bat podore gucia ${ }^{13}$ duebena ${ }^{14}$ baitan. Bigarrena siñestia dela aita. Yrugarrena siñestia dela semea. Laugarrena siñestia ${ }^{15}$ dela Esp[i]ritu Santua. Bozgarrena siñestea dela criadorea. Seigarrena siñestea dela salbadoria. Zazpigarrena siñestea ${ }^{16}$ dela glorificadoria ${ }^{17}$. Guizontasun santuari ${ }^{18}$

2 Beti iduquiceco etan] Ez da erraza zentzua harrapatzen, 'beti haietan izateko' esan nahi duela dirudi; alegia, gurutzea kopetan, ahoan eta bularrean izateko, baina Nafarroako beste dotrina zaharretan ez da horren ordainik. Satrustegik iduquicecoetan mantentzen du, eskuizkribuan bezala.

3 santiguacea] santig- ondoren tatxadura dago eta jarraian guacea gehituta.

4 bularretaraño] esk. bularrateraño. Zalantzarik gabe hutsa dago hitz honetan, baina bularrarteraño ere izan liteke. Dena den, testuan bertan bularretan agertzen denen, bularretaraño zuzendu dugu. Satrustegik, ordea, bularrateraño mantendu zuen.

5 besala] esk. besalala. Irakurketa aski ziurra da, eta argi eta garbi jartzen du besalala; Satrustegik ere hala dakar. Halere, testuan bertan beste pasarte batzuetan bezala agertzen da, neutralizaziorik gabe. Gainera, testuan ez dago txistukariaren neutralizaziorik bokal artean.

6 Ygan] $<$ n $>$ lerro artean gehitua.

7 duenaren] $<$ a $>$ eta $<$ r $>$-ren artean orban bat dago, $<$ c $>$ edo $<$ l $>$ izan daiteke.

8 Chatolicua] ziurrenik errata da, eta Catholicua behar luke hitzaren erabilera tradizioaren arabera.

9 zazpiac] jarraian tatxaturik dire dator.

10 Jaungoycotasunari] esk. jaungocotasunari. Idazlearen usus scribendi-ari jarraituz, $<\mathrm{i}>$ eta $<y>$ berrezar genezake, baina gehienetan $\langle y\rangle$ duenez, hala zuzendu dugu.

11 eguiazcoari] lehen $<$ i $>$ lerro artean.

12 dagosquionac] bigarren $<0>$ lerro artean.

13 podore gucia] lerro artean.

14 duebena] beharbada errata dubena-ren ordez.

15 siñestia] esk. sinestia.

16 siñestea] esk. sinestea.

17 glorificadoria] aurretik salbadoria dago idatzirik baina ondoren tatxaturik.

18 Guizontasun santuari] hasieran guizontasunari idatzia, ondoren -ari tatxatu eta lerro artean gehitu zen santuari. 
dagosquionac dire hoc. Lenbicicoa siñestia Jesuchristo gure jauna guizontasunas bezanbaitean ${ }^{19}$ concebitu cela Espiritu Santuaren obras. Bigarrena siñestia yayo cela Santa Maria virg[i]naganic, ura virgen geldicen cela, erdi biño len, erdician eta erdiaz guero. Yrugarrena siñestia padecitu zuela pasionia eta eriocia gu becatarien ${ }^{20}$ salbaciagatic. Laugarrena siñestea ${ }^{21}$ yauci cela infernuetara eta atera cituela santuven arimac, ceñec vaizaunden ${ }^{22}$ aren etorce santuaren beguira. Boscarrena siñestea bistu cela irugarren egunean yletaric. Seigarrena siñestea ygan cela ceruetara eta dagola yarriric J[a]ungoyco ayta podore gucia duenaren escuñeco aldean. Zazpigarrena siñestea etorrico dela vicien eta yllen ${ }^{23}$ juscacera, onei emaiteco gloria ceren guardatu citusten aren mandamentu santubac; gaistuei betico pena, ceren guardatu echitusten.

$<3>$ Jaungoycoaren legueco mandamentu santuac dirade amar. Lenvicico ${ }^{24}$ irurac Jaungoycuaren onrari dagosquionac eta verce zazpiac lagun projimuaren provechuari. Lentabicicua Jaungo[y] $\operatorname{co}^{25}$ bat mayta dazagulla ${ }^{26}$ gauza guciac baña gueyago $^{27}$. Bigarrena estaguigula iuramenturic banoqui. Yrurgarrena ${ }^{28}$ bestaegan $^{29}$ santifica ${ }^{30}$ dazagula. Laugarrena ayta eta ama onrra dazagula. Bosgarrena nior ill eztecegula. Seygarrena araguiazco beccaturic eguin ${ }^{31}$ estazagula. Zazpigarrena deusic ebatchi estezagula. Zorcigarrena falso testimonioriq alsa ${ }^{32}$ estezagula eta es guezurriq erran. Bedezigarrena ${ }^{33}$ berceren senarriq edo emasteriq desea estecegula.

19 bezanbaitean] ez dut beste inon aurkitu aldaera hau, baina Beriainek adibidez zenbait : zeinbat txandaketa du.

20 becatarien] ez dago ziur becatarien ala becatorien jartzen duen. Satrustegik ere becatarien dakar.

21 siñestea] esk. sinestea.

22 vaizaunden] lehen $<\mathrm{n}>$ hori bigarrenak eragindako duplografia izan daiteke.

23 illen] esk. il-len.

24 lenvicico] jarraian tatxaturik -ac dago.

25 Jaungoyco] esk. jaungoco. Idazlearen $u s u s$ scribendi-ari jarraituz, $<\mathrm{i}>$ eta $<\mathrm{y}>$ berrezar liteke, baina gehienetan $<y>$ duenez, hala zuzendu dut.

26 dazagulla] <ll> ez bide da sabaikaritzat hartu behar; begira beherago dazagula, estazagula eta estezagula, $<$ l>rekin.

27 gueyago] $<$ u lerro artean.

28 Yrurgarrena] esk. yrurgarena.

29 bestaegan] irakurketa ez da erabat ziurra, eta <e>-ren ordez, <l> ere irakur daiteke, Satrustegik egin bezala. Interpretazioa oso erraza ez bada ere, pentsa daiteke Sanzberroren nahia zela bestaetan 'festetan' idaztea eta $<\mathrm{g}>$ hori, beharbada, aurreko hitzak duenaren eraginez izatea. Ideia honen alde egiten dute beste lekukotasun batzuek; Beriainek dotrinan honelaxe dakar: Irurgarrena, ygandeac eta iayac beguira diçagula. Elizalderen 1735 ko dotrinan ere 'jaiak begiratzea' da Jaungoikoaren legeko hirugarren mandamentua. Gutxi diren arren, XVIII. mendeko adibide batzuek - $a$ duten hitzek bukaera hori mantentzen dute: honraetan eta puntaen daude 1729ko sermoi batean eta bienaventuranzaen dakar Elizalderen dotrinak 1735ean (Reguero, 2017, 550. orr.).

30 santifica] esk. satificadazagula.

31 eguin] esk. enguin.

32 alsa] aurretik zerbait tatxaturik.

33 Bedezigarrena] esk. Bedezi-/-cigarrena; ziurrenik duplografiaz. Hala ere, Satrustegik bederecigarrena dakar. Eskuizkribuan ikus daitekeenez, $-z i$ - gainerako letrak baino lodiago eta ilunxeago dago, baina ez da arazo handirik $-z i$ - irakurtzeko. 
Amargarrena berceren ontasuniq desea estecegula. Amar mandamentubac daude bietan: Jaungoyco bat maytacean gauza guciac baño gueyago eta lagun progimua gueuren buruaq bezala. Amen.

\section{HIZKUNTZA AZTERKETA}

Fonologia aldetik berrikuntza batzuk ditu dotrina honek, bereziki bokaletan: $o a>u a$ bilakabidearen kasu batzuk ditugu: Jaungoycuaren, lentabicicua, devociua. Dirudienez, aski berritzaile da Bortziriak alde horretatik, ez baita lekukotasun zaharragoetan bilakabide hori maiz ageri (Reguero, 2017, 549. orr.). Orobat $e a>i a$ bilakabideaz; horren adibide gehiago ditu testuak, hauek esaterako: biar 'behar', ciñacia, criazallia, podoriaren, siñestia, glorificadoria. Dena den, salbuespenak ere badaude: gurucean, fedean, egitea, etab. Bestalde, hiatoetan $u V>u b V$ bilakabidea dugu: auban, zuben, duebena, santuven, santubac, mandamentubac. Ikus daitekeenez, hiru ezaugarri horietan berritzaile suertatu da Bortziriak. Nafarroako testu zaharretan ez da erraza halakoak aurkitzen. Dena den, orduko Lapurdiko eta Gipuzkoako ipar-ekialdeko testuetan agertzen dira: 1721eko Irungo Udaleko euskarazko lekukotasun batzuetan nubenac 'nuenak' eta contubac 'kontuak' agertzen dira, besteak beste (Reguero, 2017, 549. orr.). Lapurdin ere ez da falta halako adibiderik: Le Dauphin itsasontziko 1757ko euskarazko gutunetan bilakabide horren adibideak badaude (Lamikiz, Padilla \& Videgain, 2015). Nafarroan ezaugarria aurreko mendean ere lekukotzen da Bortzirietan: escussatuba eta contuba agertzen dira, besteak beste, Miguel Elizalde etxalartarrak eta bere izebak idatzitako gutunetan (Reguero, 2017, 309. orr.). Halere, Lesakakoa zen Mikelestorenak ez dakartza bilakabide horiek. Bokalez den bezainbatez, $e-u>i-u$ gertatu da 'eduki' aditzean: $y d u q u i c e r a, i d u q u i c e c o$. Mikelestorenak badu iduki aldaera. Era berean, podore aldaeran ikus dezakegunez, $o-e>o-o$ gertatu da, ia Nafarroa osoan bezala.

Kontsonanteei dagokienez, $-r(t) z-$ multzoa dago verce adibidean. Halere, Bortzirietan bertan Mikelestorenak beste dakar beti, XVIII. mendearen erdialdean. Bestalde ${ }^{*} j$-ren ahoskera sabaiaurrekoa dela dirudi: yayo, iauci, iarriric, iuscacera. Txistukarietan, ez + zituzten bilketan echitusten dugu; dena den, ezin jakin afrikatu sabaikaria edo bizkarkaria islatzen duen. Igurzkarien neutralizazioa bide dago, bereziki herskari aurretik: gaisqui, gastuetaric, fedesco, dagosquionac, gaistuei, baina eguiazcoari. Kasu batean hitz amaieran dugu: es; halere, obraz eta graciaz ditugu. Oro har, bokal artean ez da txistukari igurzkarien arteko neutralizaziorik: eguizu, nacusazun, gucia, baina besala dago behin, bezala ere badagoen arren. Mikelestorenak ondo bereizten ditu, testuinguru guzietan, afrikatu eta igurzkariak. Azkenik, sabaikaritzea dugu, bai diptongo ondoren bai /i/ bokalaren ondoren: siñestacen, bularretaraño. Hotsen aurkezpena amaitze aldera, interesgarriak dira ozen ondoko herskariak, ez baitira ahostun egiten: pensamentu, lentabicicoa, iuramentu. Hori horrela, goi-nafarrerazko sandu aldaeraren ordez, santu erabiltzen da. Mikelestorenak pensamentu, urriquimentu, adimentu eta santu dakartza. Egun, santu dago Bortzirietan (Zelaieta, 2011).

Morfologiaz den bezainbatean, hirugarren graduko erakusleetan etan 'haietan' dugu: beti iduquiceco etan. Horrez gain, ekialde zabaleko berrikuntza den baita- agertzen da 
bizidunen kasuetan: podore gucia duena baitan, Jesuchristo gure jauna baitan, siñestatcen dut Espiritu Santua baitan. Hala eta guztiz ere, arkaismo gisa, -ganik duen adibiderik bada: yayo cen Virgina Mariaganic. Mikelestorenak - gan- baizik ez dakar. Ablatiboan gastuetaric, hiletaric agertzen den arren, gastuetatic ere badago; azken aldaera hori da Mikelestorena lesakarrak beti dakarrena. Bortzirien ondoan, Baztanen -etaik eta -etarik dakartza 1791ko sermoiak (Lekaroz, 2006). Interesgarria bide da ezaugarri hori, Nafarroako mendebaldea erdialde/ekialdetik bereizten duen isoglosa baita. Mendebaldean -etatik forma berria dago, gainerakoan -eta $(r) i k$ aldaera zaharra. Salaberrik (2000, 896. orr.) dioenez, Iruñetik iparraldera eta ekialdera erabiltzen da -etarik; aldiz, hegoaldean eta mendebaldean -etatik forma berriagoa dago. Egungo datuak erabiliz, Zelaietak (2011, 201-202. orr.) Urdazubiko, Zugarramurdiko eta Baztango mintzoak mendebaldeko eta erdialdeko mintzoetatik bereizteko ezaugarritzat dakar. Horrezaz landara, goinafarrerak duen berrikuntzetarik bat da instrumentalaren aldaera apikaria. Dena den, hizketa batzuek ez dute berrikuntza hori, eta Bortziriak kanpoan da (Zelaieta, 2011, 188. orr.; Reguero, 2017, 576-578. orr.); beraz, dotrina honetan, instrumentalean bizkarkaria eta apikaria ditugu: batetik, obraz, graciaz eta, bestetik, obras eta guizontasunas. Bide batez, Mikelestorenak ere halaxe du. Nafarroako iparraldeko ibarrak (Baztan eta Bidasoa) gainerako Nafarroako eskualdeetatik bereizten duen beste ezaugarria da latinetik datozen maileguetan -ione egitea, ez -io; hori horrela, Sanzberrok -ione du: comunionia, pasionia. Hala ere, -tione > -zio egin da: barcacioa. Ezaugarri horretan, Bortziriek Lapurdirekin bat egiten dute, eta gainerako Nafarroatik aldentzen dira (Reguero, 2017). Edonola ere, Mikelestorenak beti du -zio: barcacio, devocio, oracio. Izenordainetan Gipuzkoako eta Nafarroako autoreengan ohikoa den gueuren aldaera pleonastikoa dugu. Mikelestorena lesakarrarena da ondokoa: gueren damuarequin zure damua.

Aditz morfologiari dagokionez, aditz izenetan -iten mantentzen da: emaiteco; halere, adibide bakarra da. Dena den, Mikelestorenak egoteac eta, behin eta berriz, ematen ditu. Horrezaz landara, izan aditzaren iraganeko erroa $-e-$ da beti: il cen, concebitu baicen, yayo cen. Orainaldiko hirugarren pertsona pluralean behin dirade agertzen bada ere, gainerakoetan dire dago, baina ez dirudi ia > ie bilakabidea denik, ez baita beste adibiderik, beraz berrinterpretazioz izan liteke direla batetik abiatuta. Adizkiaren forma hori oso ohikoa da Nafarroan, baita $i a>$ ie bilakabidea ez duten lekuetan ere. *Edun aditzaren erroa $-u-$ da: $d u g u$. Mikelestorenak ere, nagusiki, $-u$ - badu ere, dezu ere erabiltzen du. "Ezan adizkietan -a- agertzen da: mayta dazagulla, onrra dazagula, eguin estazagula, baina ez beti eta sistematikoki: nior ill eztecegula, deusic ebatchi estezagula, alsa estezagula... Subjuntibo trinko bat ere agertzen da: estaguigula 'ez dezagula egin'. Emandako adibideetan ikus daitekeenez, indikatibokoak ez diren perifrasietan aditzoina erabiltzen da: mayta dazagulla, onrra dazagula, alsa estezagula, baina ebatchi estezagula. Azkenik, egokitu aditzean dagozca eta dagosquio adizkien arteko txandaketa dago. Erdialdeko idazleen artean, ohikoa bide da bi formak erabiltzea; Mendiburuk eta Kardaberatzek, adibidez, biak dituzte.

Sintaxi aldetik TOGEN egitura erabiltzen da: il cen gure salbaceco, vicien eta ilen iuscacera. Halere, egitura hori espero genukeen kasu batean ez da halakorik: culpatic gu ateraceco. Bestalde, konparaziozko perpausetan baño eta baña agertzen dira: gauza guciac baña gueyago eta gauza guciac baño gueyago. 
Lexiko aldetik aipagarri dira goi-nafarrerazko ondokoak: igan 'igo' erabiltzen da $\mathrm{Na}$ farroako iparraldean, erdialdean eta ekialdean, eta halaxe dakar Sanzberrok, Mikelestorenak bezala. Bestalde, iru agertzen da, baina -garren atzizkiarekin yrugarren eta yrurgarren formak dakartza dotrinak. Zenbakiez ari garela, aipagarri da bedezigarren adibidean, bedezi 'bederatzi' Bortzirietako aldaera agertzen dela. Azkenik, siñestacen aldaera nafarraren ondoan, siñestea aldaera orokorra ere badago. 


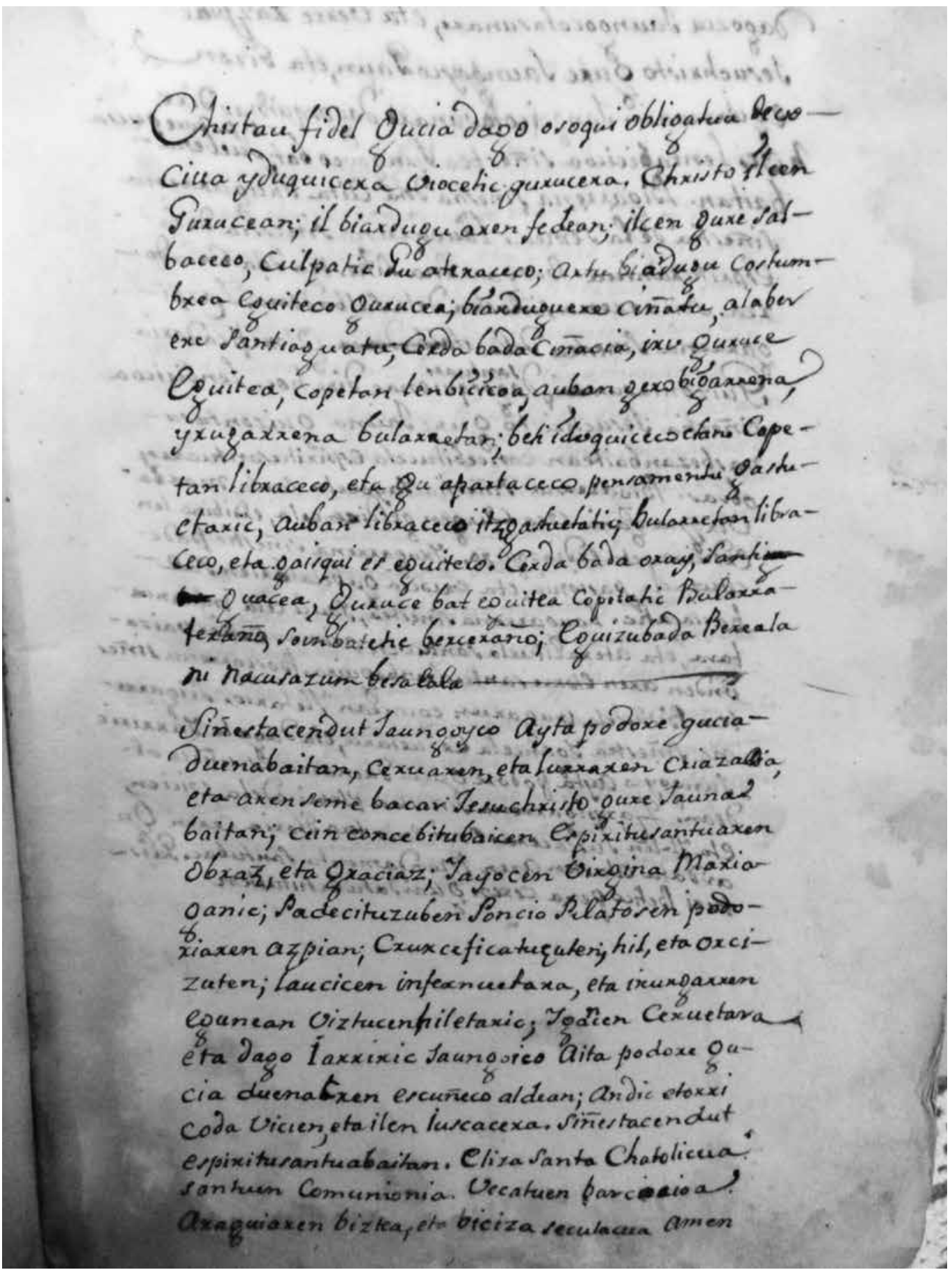




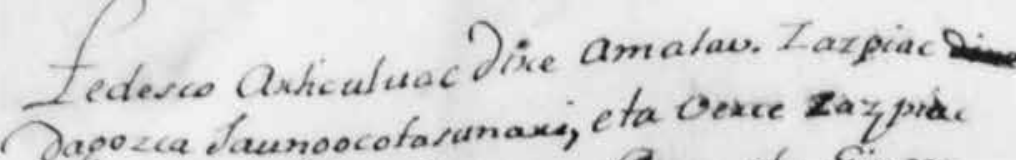

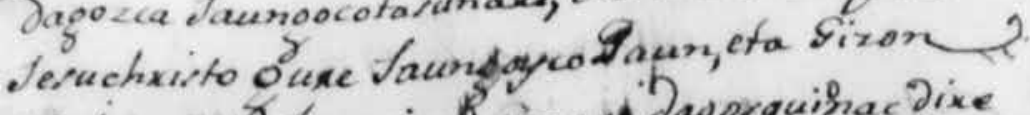

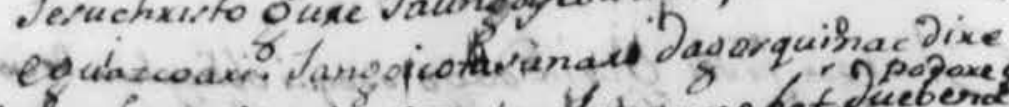

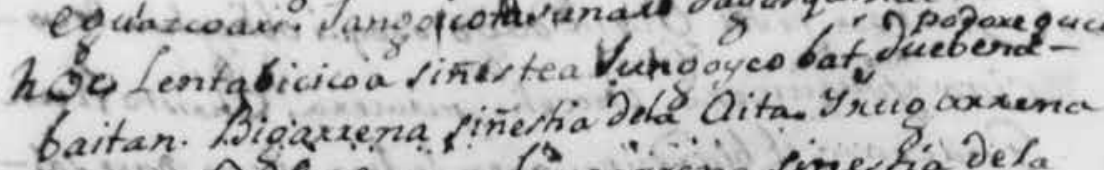

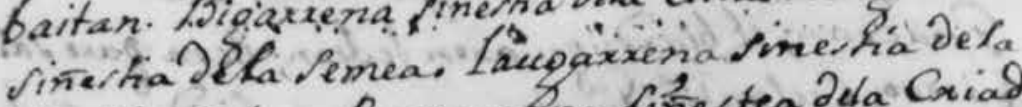
erpitrieantua. Borqaxina inertea dela Cxiadoxea Seio axkena pitestea Dela Palbadoxiar Tazpioaxueria Pinertea Dela Oloxificadoxia Guizontarunim Jagosquionac Dixe hoc. Senbicicoa viñertia Jeruchxirto Ouxe Jauna Ouizontarunarbezanbaitean concebitucela espixiturantuaxan obrar. Biodxcena Mriertia Tayocela Panta maxila vixona ganic uxa cirgen géficencela, emibiio len

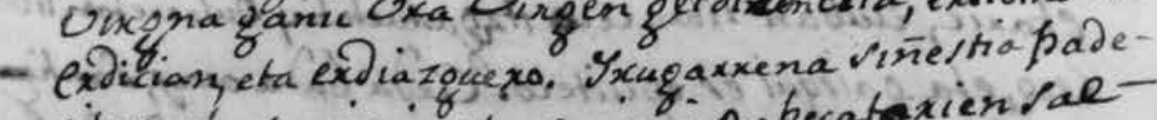
cituzuela parioria, eta excocia oubecatexiensalbaxiapatic. Lamoarxena inestea, Yaucí cela inferenfara eta atexacifuela danteven axima ceñecuaiza-

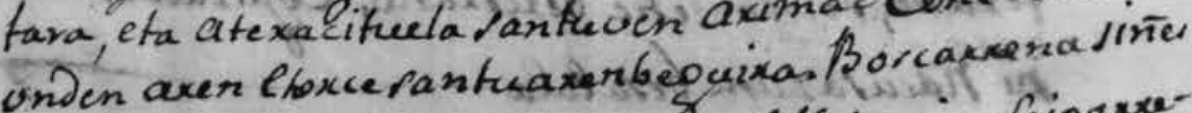

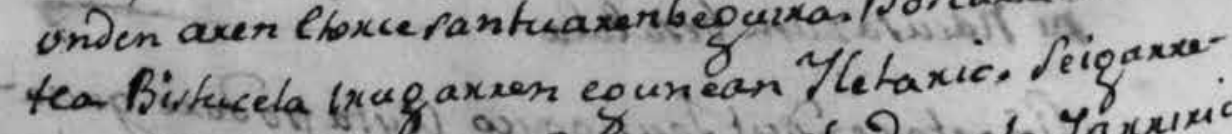
dina riñertea Yoancela Cexciefaxa, efa Jaodola Yaxumic

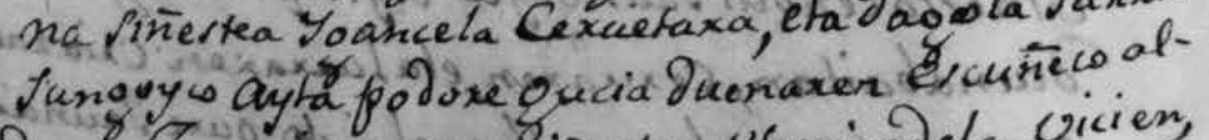

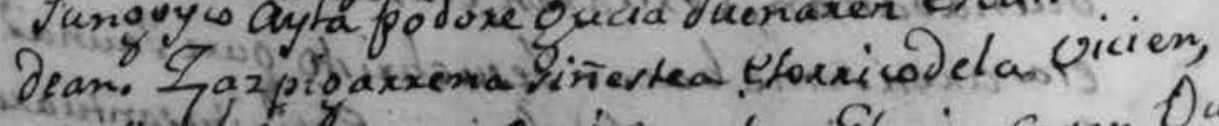

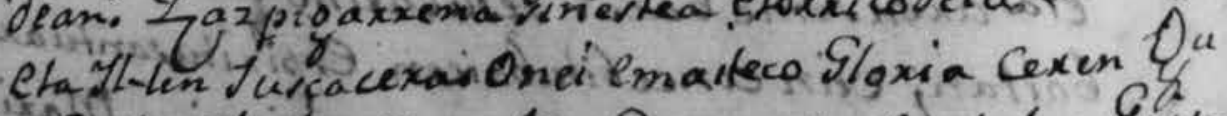

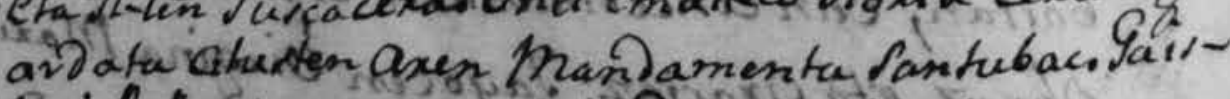

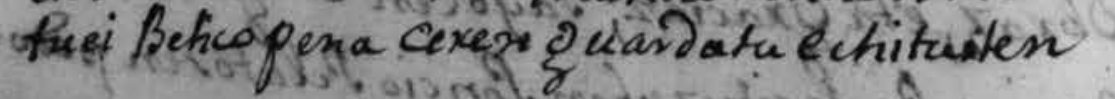

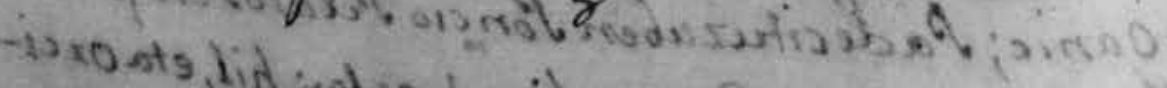




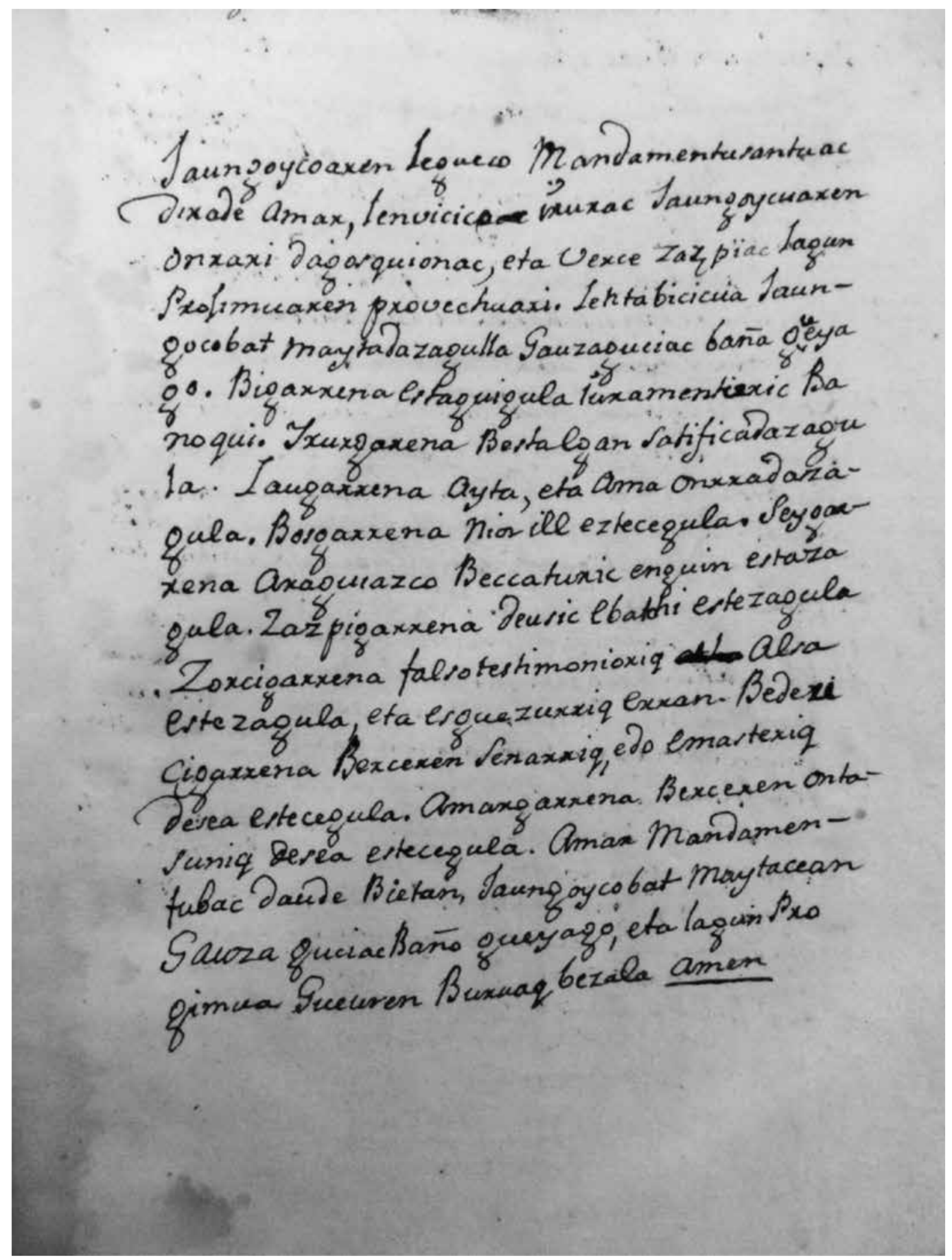




\section{ERREFERENTZIAK}

Lamikiz, X., Padilla, M. \& Videgain, X. (2015). Othoi çato etchera. Le Dauphin itsasontziko euskarazko gutunak (1757). Lapurdumen ale bereziak 2.

Lekaroz, G. (2006). Antzinako baztanera: XVIII. mendeko prediku argitaragabe bat. FLV, 101, 69-94.

Lekaroz, G. (2014). Sanzberro, Juan Bautista (1701-1751). Lingua navarrorum. Euskara eta Nafarroa, atzo eta gaur - Navarra y el euskera, ayer y boy [bloga]. Hemendik hartua: http://linguanavarrorum.blogariak.net/2014/09/23/ juan-bautista-sanzberro-1701-1751/ (kontsulta: 2017/09/28).

Mikelestorena, J. (1751). Cerura nai duenac ar dezaquen bide erraza. Iruñea: Martin Joseph Radaren etxea.

Reguero Ugarte, U. (2017). Goi-nafarrera arkaiko eta zaharra: azterketa eta testuak (doktorego tesia). UPV/EHU.

Salaberri Zaratiegi, P. (2000). Iruñerriko eta inguruko ibarretako euskararen gainean. Euskera, 45(2), 881-920.

Satrustegi, J. M. (1978-79). Contribución al fondo de textos antiguos vascos. ASJU, 12-13, 225-245.

Satrustegi, J. M. (1987). Euskal testu zaharrak I. Iruñea: Euskaltzaindia.

Zelaieta, E. (2011). Baztan-Bidasoako bizkeren azterketa dialektologikoa. Iruñea-Bilbo: Nafarroako Foru Aldundia-Euskaltzaindia. 